\title{
LIMITES E POTENCIALIDADES DO SEGURO FRENTE OS EVENTOS CLIMÁTICOS EXTREMOS
}

\section{LIMITS AND POTENTIAL OF INSURANCE TO COPE WITH EXTREME WEATHER EVENTS}

Fernanda Dalla Libera Damacena ${ }^{1}$

\section{Resumo}

A natureza ou propósito do contrato de seguro tem como núcleo principal a transferência de risco. Excepcionalmente, algumas situações acabam excluídos desse portfólio. Os eventos extremos, decorrentes ou correlatos às mudanças climáticas são exemplos dessa exclusão. O presente artigo analisa os limites e potencialidade da relação entre o contrato de seguro e os efeitos adversos das mudanças climáticas. A pesquisa será norteada por uma postura construtivista voltada à gestão de riscos atuais e futuros. Como resultados da presente investigação destaca-se que para o seguro se tornar uma realidade mais abrangente no Brasil, uma série de barreiras precisam ser superadas. A primeira delas é equalizar dois requisitos: i) os prêmios devem refletir os riscos; mas ii) a premissa do valor dos prêmios não deve perder de vista questões como justiça e acessibilidade. Nesse contexto, o modelo parceria público-privada representa o que há de mais contemporâneo e contributivo para uma evolução positiva do círculo de gestão de risco de desastre. Exemplos de programas de seguro voltados a eventos climáticos extremos, desenvolvidos no âmbito do direito comparado, demonstram a viabilidade e compatibilidade dessa espécie de instrumento normativo e econômico como parte integrante de uma estrutura compensatória das vítimas de eventos extremos no sistema brasileiro.

Palavras-chave: mudança climática, seguro, evento extremo, direito

\section{Abstract}

The purpose of the insurance contract has as its main core the transfer of risk. Exceptionally, however, some situations are excluded from this portfolio. Extreme events, arising or related to climate change are examples of this exclusion. This article analyzes the limits and potentiality of the relationship between climate change and the insurance contract. The research will be guided by a

\footnotetext{
1 Doutora e Mestre em Direito Público. Especialista em Direito Público. Professora da graduação e pósgraduação na Unisversidade do Vale do Rio dos Sinos. Coordenadora da Especialização em Direito Ambiental Unisversidade do Vale do Rio dos Sinos. Autora de artigos científicos e do livro Direito dos Desastres. Advogada. E-mail: fer.dl.damacena@gmail.com
} 
constructivist approach focused on the management of current and future risks. As results of the present investigation it is highlighted the need to equalize two requirements: i) the premiums should reflect the risks; but ii) the premise of the value of the prizes should not lose sight of issues such as justice and accessibility. In this context, the public-private partnership model is the most contemporary and contributory to a positive evolution of the disaster risk management circle. Examples of insurance programs focused on extreme weather events, developed under comparative law, demonstrate the viability and compatibility of this kind of normative and economic instrument as an integral part of a compensatory structure for the victims of extreme events in the Brazilian system.

Keywords: climate change, insurance, extreme event, law

INTRODUÇÃO

A natureza ou propósito do contrato de seguro tem como núcleo principal a transferência de risco. Nesse contexto, pessoas vislumbram a probabilidade de específicos tipos de perda e buscam proteção em relação às suas consequências (para si, propriedades e bens). De regra, apólices de seguro são subscritas para assegurar perdas determinadas, independentemente da causa do dano. Excepcionalmente, contudo, alguns eventos acabam excluídos desse portfólio. Os eventos extremos, decorrentes ou correlatos às mudanças climáticas são exemplos dessa exclusão.

Por pertencer ao grupo dos contratos privados, o seguro está sob o manto de certo grau de autonomia na determinação do escopo da cobertura a ser ofertada. Mas frente às mudanças climáticas e seus efeitos negativos, uma releitura dessa espécie de contrato precisa ser considerada. Uma observação diferenciada das funções do contrato de seguro é desenvolvida pela revisão da literatura, jurídica, econômica e financeira, que o considera dentre os instrumentos capazes de contribuir para a compensação das vítimas de eventos climáticos extremos. No Brasil, essa interpretação diferenciada é possível pela postura inclusiva e solidária da Constituição Federal e Código Civil brasileiros.

A partir dessa perspectiva, e tendo em conta a relevância da reflexão acerca dos instrumentos compensatórios frente à eventos climáticos no País, o artigo analisa os limites e potencialidade da relação entre o contrato de seguro e os efeitos adversos das mudanças climáticas. 
O artigo será orientado por uma postura metodológica construtivista, voltada à gestão de riscos atuais e futuros, complementada pelas técnicas de pesquisa bibliográfica, documental e jurisprudencial. Essa linha de raciocínio privilegia a temática da complexidade, dos paradoxos e dos riscos, e proporciona um ponto de vista qualificado para observar não somente o problema proposto, mas o Direito e a sociedade (ROCHA, 2018).

O método auxiliar de pesquisa será o comparativo, o que permite o cotejo com a experiência normativa e jurisdicional estrangeira (MEZZAROBA, 2009, p.1) acerca dos mecanismos de compensação em matéria de eventos extremos (como os climáticos). O foco primordial da comparação centrar-se-á no direito dos desastres comparado, especialmente no que tange às estruturas normativas e experiências correlatas aos instrumentos compensatórios para vítimas de eventos extremos. O cunho exploratório (VAN HOECKE, 2011, p. 5) dessa metodologia pode contribuir para processos de desenvolvimento do Direito dos Desastres e resiliência das cidades no Brasil.

Sete tópicos compõem a estruturação do artigo. O primeiro introduz conexão entre o contrato de seguro e os eventos extremos. Na sequência, a partir do desvelamento da noção de segurabilidade, são destacadas as principais limitações do seguro frente aos eventos extremos correlatos ao clima. Ainda, com o objetivo de demonstrar sua importância no âmbito dos instrumentos compensatórios na atualidade, dados referentes aos custos dessa espécie de eventos são apresentados, bem como as vantagens e obstáculos para sua consolidação no mercado brasileiro. No campo das alternativas existentes no direito comparado, apresenta-se o exemplo da compulsoriedade do seguro Francês, as hipóteses do resseguro e da transferência de risco no mercado de capitais, bem como as alternativas de programas de seguro bem-sucedidas em países em desenvolvimento, como o sistema de microsseguros e os exemplos do Caribbean Catastrophic Risk Insurance Facility ("CCRIF")' African Risk Capacity e o Up Loan Program CT Shore.

\section{SEGURO E EVENTOS EXTREMOS: NOÇÕES PRELIMINARES}

Algumas características do contrato de seguro o tornam um mecanismo de compensação muito peculiar, peculiaridade esta que é exacerbada quando observado do ponto de vista das 
mudanças climáticas. Dentre essas características estão: i) a perda potencialmente devastadora do segurado; ii) incerteza de que a perda venha a acontecer; iii) o estabelecimento do equilíbrio entre os que sofreram perdas e os interesses das organizações (públicas e privadas). De regra, são foram as razões apresentadas durante muito tempo pelo mercado privado segurador para não disponibilizar certos tipos de cobertura. (BROWN; SECK, 2012, p. 545-546). Esse é o caso, por exemplo, da inundação e terremotos no campo dos denominados desastres "naturais". ${ }^{1}$

A principiologia de base do seguro também explica essa postura. De acordo com o princípio da fortuidade, a aleatoriedade da perda em relação a questões como a) quando acontece, b) a quem atinge e c) sua extensão, são fundamentais para a garantia da subsistência das seguradoras. Logo, quando a probabilidade de perda potencial se torna muito provável, as seguradoras respondem de duas formas: i) limitam a cobertura através de contratos mais restritivos ou exclusões mais amplas (ou, ainda, pela retirada do tipo específico de cobertura por completo); ou ii) aumentam as franquias. Nessas circunstâncias, "[...] os pressupostos de cálculo de custos e outras decisões de subscrição baseiam-se nos piores cenários possíveis". (BROWN; SECK, 2012, p. 548).

Assim, ainda que o seguro seja ofertado, o mesmo pode se tornar muito caro, o que é um sério problema para países onde a população mais exposta não pode arcar com esse tipo de custo. Não por outra razão, e apesar das dificuldades de implementação, estudos sobre desastre e a ampliação dos contratos de seguro têm recebido cada vez mais atenção nos países em desenvolvimento. Dentre as explicações para tanto estão a insuficiência do instituto da responsabilidade civil para compensar vítimas de eventos extremos; e o fato de o Estado (e em última medida o contribuinte) acabar agindo como segurador universal nas ações de resposta, ou como réu em quase todas as demandas judiciais.

O enfrentamento do paradoxo entre o princípio da fortuidade com outro princípio do seguro, a proteção do consumidor (o que abrange suas expectativas), é outro fator a ser considerado nesse processo. Trata-se de tensão que precisa ser observada em termos normativos (a fim de que o contrato passe a assumir dimensões mais abrangentes diante de novas necessidades sociais) ou ponderada em decisões judiciais. Na impossibilidade de oferta de determinadas coberturas devido ao ambiente de risco prevalente, os consumidores ficam desprotegidos. Nesse caso, ao judiciário, muitas vezes, caberá o papel de mediar os possíveis conflitos e as razoáveis expectativas das partes contratantes. (BROWN; SECK, 2012, p. 547).

Essas questões estão em franco debate nos Estados Unidos na atualidade, especialmente após as inundações e outros danos ocasionados pelos furacões Harvey e Irma. Das informações até 
agora divulgadas, sabe-se que residentes da Flórida, Geórgia, Alabama e Carolinas podem ter que pagar uma parcela maior dos danos do que esperavam, porque as seguradoras têm aumentado constantemente as franquias de cobertura de vento de furacões e estabelecido novos limites, após a ocorrência dos eventos extremos. Por essa razão, alguns proprietários devem enfrentar algumas mudanças, especialmente de custos. Essa é a primeira linha de um carretel de grandes discussões, pois as informações nem sempre são claras ou compreensíveis para todos os consumidores.

As denominadas "anti-concurrent-causation clauses" retratam um sério problema de comunicação entre seguradoras e consumidores. São cláusulas que excluem a cobertura de danos causados pelo vento, se uma "inundação sem seguro" ocorrer ao mesmo tempo. (HEMBREE, 2017). Essas cláusulas são muito difíceis de serem compreendidas pelos consumidores, já que a maioria das pessoas não acredita que sua companhia de seguros venderia uma política com cobertura de vento que poderia desaparecer através de uma cláusula escondida no fundo da linguagem da apólice. Essas cláusulas são muitas vezes ambíguas e acabam sendo o que garante a negativa de coberturas ou o pagamento de valores menores. Nesses casos o recurso subsequente acaba sendo o poder judiciário, tanto que inúmeros escritórios de advocacia já trabalham neste propósito atualmente nos estados americanos atingidos. (HEMBREE, 2017). O outro lado da moeda, é o drama da insolvência para muitas seguradoras. Diante de eventos dessa magnitude, nem mesmo as solventes estão necessariamente preparadas. (HEMBREE, 2017).

Brown e Seck (2012), argumentam que um mercado mais restritivo é problemático em termos sociais e tem o condão de desencadear pressões por legislações capazes de: regular políticas de preços; instituir o envolvimento direto do governo no fornecimento de seguros, ou alterar legislação específica existe. (BROWN; SECK, 2012). Uma alternativa para a questão dos eventos extremos seria o estabelecimento não apenas da transferência de risco em circunstâncias não previstas, mas a criação de mecanismos para que isso se torne possível, conforme se verificará na sequência. Contudo, há que se ter em conta que a imposição de obrigações às seguradoras sem considerações atuariais realistas é extremamente improvável de ser bem-sucedida. Um dos argumentos nesse sentido é que, em algumas circunstâncias, determinadas obrigações podem representar a receita para uma calamidade financeira. (BROWN; SECK, 2012). Por essa razão, o equilíbrio entre a possibilidade real da oferta do seguro e sua necessidade diante de eventos extremos requer, inicialmente, a compreensão do que significa a segurabilidade, conceito trabalhado a seguir. 


\section{SEGURABILIDADE NO CONTEXTO DOS EVENTOS EXTREMOS}

A fim de ponderar o seguro como um instrumento de compensação para vítimas de eventos extremos, importa esclarecer de que espécie de seguro se está tratando. A literatura especializada (BRUGGEMAN, 2010; FAURE; HARTLIEF, 2006: KUNREUTHER; MICHEL-KERJAN. 2007) na matéria seguro e desastres tem referenciado que o seguro de responsabilidade civil se aplica com maior adequação aos desastres oriundos da atividade econômica (os denominados man-made disasters) enquanto o first party insurance aplicar-se-ia aos desastres "naturais". Nessa última espécie a vítima contrata o seguro como forma de proteção contra danos futuros, caso em que a cobertura do seguro é desencadeada pela ocorrência do dano, não por responsabilidade. (FAURE; BRUGGERMAN 2008). Trata-se, portanto, de seguro diverso do seguro de responsabilidade civil.

O princípio subjacente a essa espécie de seguro é que a companhia de seguros, em princípio, efetua o pagamento logo que ocorre um dano, desde que seja comprovado que o dano específico é um risco segurado coberto pela apólice. Dentre suas vantagens está o fato de as vítimas poderem adquirir coberturas de acordo com suas necessidades; e o principal, a seguradora pode (através do controle de risco moral) cobrar prêmios de acordo com o risco. (FAURE, M.; FAURE, M.; WIBISANA, 2013).

Importante, essa espécie de seguro não diminui as perdas globais de um evento adverso, mas espalha seu impacto financeiro, habilitando aqueles em risco a pagar um prêmio relativamente pequeno para que possam ser protegidos contra uma grande perda que tem pouca chance de ocorrer. Por isso, o seguro das perdas reflete apenas uma parte do dano econômico total infligido por um desastre. (KUNREUTHER; MICHEL-KERJAN, 2007).

O uso do seguro como ferramenta de transferência de risco tem cinco características principais: permite a disseminação de risco entre as partes; reduz a variância do risco para cada pessoa; permite a segregação de risco; encoraja medidas de redução de danos; e fornece uma ferramenta para monitorar e controlar o comportamento. (FREEMAN; KUNREUTHER, 2002).

O conceito de seguridade pode ser compreendido a partir de um exemplo. Considere-se um seguro padrão no qual os prêmios são pagos por um período para cobrir perdas durante um intervalo (geralmente um ano). De regra, duas condições precisam ser atendidas antes que os provedores de seguros estejam dispostos a oferecer cobertura contra um evento incerto. A primeira é que o "provedor seja capaz de identificar, quantificar e estimar as chances de ocorrência do evento, assim como a extensão das prováveis perdas. Em segundo lugar, a seguradora precisa poder estabelecer 
prêmios para cada cliente potencial ou classe de clientes", (BOTZEN; VAN DEN BERGH, 2008, p. 417) o que se corresponde à denominada segregação dos riscos. Se tais condições forem satisfeitas, um risco é considerado segurável. (KUNREUTHER; MICHEL-KERJAN, 2007).

Em matéria de evento climático extremo, importante mencionar alguns desafios impostos ao setor de seguros. Além da conhecida incerteza climática, questões socioeconômicas como a pobreza e a vulnerabilidade têm sido consideradas como causas altamente relevantes para o aumento dos danos. Ademais, características muito comuns em países em desenvolvimento costumeiramente negligenciadas, como a falta de controle em relação ao uso da terra, fraca imposição ou regulamentação de códigos de edificação, tendência de crescimento populacional em áreas geográficas de risco e pouca manutenção de infraestruturas, são todos fatores que interceptam e influenciam na viabilidade do seguro para eventos extremos. (BLAZEY; GOVIND, 2007).

Apesar de tudo, o debate em torno da segurabilidade ou não dos desastres "naturais" tem crescido nos últimos tempos. As principais restrições em termos de segurabilidade giram em torno das seguintes razões: i) seleção adversa ${ }^{3}$ e risco moral ${ }^{4}$; ii) o fato de o risco catastrófico "natural" ser classificado como risco altamente correlacionado; iii) e da possibilidade de estimativa da frequência e probabilidade dessa espécie de evento, bem como sua expectativa de dano (probabilidademagnitude). (BRUGGEMAN, 2010).

\subsection{Seleção Adversa, Risco Moral e Correlação de Riscos}

A seleção adversa se manifesta quando os indivíduos de alto risco têm mais probabilidade de necessitar da cobertura do seguro que as pessoas de baixo risco. É causada por assimetrias de informações entre empresas de seguros e segurados. Esse problema pode surgir quando os indivíduos são capazes de determinar suas características de risco individuais e as companhias de seguros têm dificuldades em distinguir os bons dos maus riscos. (BOTZEN; VAN DEN BERGH).

No contexto da mudança climática, a seleção adversa não é o maior problema, pois é difícil que aqueles que estão em risco tenham mais informações vantagiosas em comparação com as seguradoras. Em geral, as últimas investem significativos valores para terem essa vantagem informacional em relação aos segurados que, de regra, não possuem condições ou não têm interesse em custear estudos de avaliação de risco.

O conceito de risco moral está ligado a um aumento nas perdas esperadas (probabilidade ou quantidade de perda condicional em um evento) causado por mudanças no comportamento do 
segurado. Um exemplo de risco moral é um comportamento mais descuidado. "Se a seguradora não puder prever esse comportamento e confiar em dados de perdas passadas de indivíduos não segurados para estimar taxas, o prêmio resultante provavelmente será insuficiente para cobrir perdas". (KUNREUTHER; MICHEL-KERJAN 2007, p. 1825). Entretanto, alternativas como contratos com cláusulas excludentes em caso de comprovação de comportamento de risco, introdução de franquias específicas, cosseguro e limites superiores de coberturas podem ser ferramentas contributivas para a redução do risco moral.

Além da seleção adversa e do risco moral, a correlação de riscos é outro fator seriamente levado em consideração pelas seguradoras no momento de estabelecer a cobertura de um evento por seguro. Essa variável está diretamente relacionada com a solvência da seguradora. Sua insolvência é possível quando muitas perdas ocorrem simultaneamente devido a um único evento. Esta situação pode surgir quando os riscos são altamente correlacionados. Por exemplo, inundações podem ter consequências devastadoras, uma vez que uma grande inundação costuma prejudicar muitas propriedades e empresas em uma área concentrada e ao mesmo tempo. Não é raro que grandes enchentes ${ }^{5}$ possam estar além da capacidade das seguradoras devido à falta de capital. Por isso é que a propagação do seguro sobre diferentes bacias hidrográficas, áreas costeiras e pôlderes ${ }^{6}$ é necessária para garantir um certo grau de independência de eventos inundáveis.

O conteúdo das razões mais comumente apontadas para a segurabilidade ou não de um risco não fornece uma resposta simples acerca da segurabilidade ou não dos desastres "naturais". Por essa razão, uma vez mencionadas e conceituadas as características mais relevantes da segurabilidade, pode-se dizer que a oferta de seguro para eventos extremos climáticos depende, basicamente, de duas condições: i) capacidade do mercado de seguro de atrair fontes adicionais de capital, capazes de financiar camadas superiores de riscos catastróficos. Isso faz com que o mercado possa operar mais completamente, mesmo nos casos onde grandes perdas são esperadas; ii) que as técnicas de modelação dos desastres "naturais" se mantenham atualizadas e refinadas, especialmente com relação ao impacto das mudanças climáticas na frequência e intensidade dos desastres "naturais". (BRUGGEMAN, 2010).

Pelas condições mencionadas é simples compreender o porquê da afirmação de que o seguro é mais eficaz para riscos envolvendo fogo, automóveis e perda de vida. Afinal, tais situações permitem estimar probabilidades e perdas muito mais facilmente. Já os riscos associados às mudanças climáticas, diferentemente, não satisfazem as referidas condições, o que a primeira vista os torna mais difíceis de serem assegurados. 
Uma forma de repensar essa noção tradicional é observar com mais cuidado as relações entre i) risco e incerteza e ii) eventos extremos e seus custos. No que diz respeito à primeira relação, o esclarecimento acerca do que é conhecido, conhecido parcialmente ou totalmente ignorado pode ser o ponto de partida para a transformação da crença de que seguro e mudança climática são incompatíveis.

Como coloca Bruggerman (2010), a falta de confiabilidade estatística não constitui motivo para a não segurabilidade do risco catastrófico, pois incerteza em relação à probabilidade de um dano é um elemento que o segurador pode, ex ante, levar em consideração no momento em que estabelece o prêmio. Ademais, a assunção de um determinado grau de risco depende da decisão de cobrí-lo ou não, o que geralmente ocorre a partir do conhecimento das probabilidades de um resultado, preferencialmente baseado um modelo de análise.

As estimativas de perdas levadas em consideração pela seguradora costumam se basear em dados passados (por exemplo, histórico de perdas do portfólio de segurados ou histórico de perdas em uma região específica), juntamente com dados sobre o que os especialistas conhecem sobre um risco particular através do uso de modelos de catástrofe. Tendo em vista que essa estimativas nem sempre têm se revelado as melhores, sobretudo frente às mudança climática, Kunreuther e MichelKerjan (2007, p. 1813-1814) propõem um modelo diferenciado, que se baseia em quatro componentes: “[...] risco, portfólio (inventário), vulnerabilidade e perda”. A partir dessa perspectiva:

\begin{abstract}
Primeiro determina-se o risco de ocorrência de um fenômeno. Na sequência realiza um inventário, da forma mais transparente possível, de propriedades em risco (o que pode ser feito por meio de coordenadas que apontem, por exemplo, a localização espacial, o tipo de construção, sua idade e o histórico de eventos extremos sofridos). Essa espécie de inventário torna possível o cálculo da vulnerabilidade ou suscetibilidade ao dano das estruturas em risco. Contudo, como o grau de vulnerabilidade varia de acordo com cada região, o ideal é que o modelo não seja único. Nessa espécie de modelo os danos possuem natureza direta e indireta. As primeiras incluem os custos de reparar ou substituição da estrutura. As indiretas abrangem a interrupção de negócios e a realocação de residentes que precisaram ser evacuados. (KUNREUTHER; MICHEL-KERJAN 2007, p. 1814).
\end{abstract}

Baseado nos resultados do modelo o segurador pode calcular o que se denomina de curva de probabilidade excedida. A curva especifica a probabilidade de um certo número de perdas serem excedidas em uma determinada localidade em um determinado período. Essa metodologia não é válida apenas para as seguradoras. Agências governamentais também podem utilizá-la para estimar 
a probabilidade de excessos de danos em uma determinada região, o que fortalece a previsibilidade do grau de assistência governamental necessária para uma determinada localidade. (KUNREUTHER; MICHEL-KERJAN 2007).

Feito o inventário, caso o segurador decida ofertar a cobertura para extremos climáticos ${ }^{7}$ surge uma etapa extremamente complexa. Trata-se da determinação do valor do prêmio, que não pode estar desconectado da garantia de lucro que garanta sua sobrevivência. (KUNREUTHER; MICHEL-KERJAN 2007). Além dessa questão, conforme já mencionado, o segurador considera a assimetria das informações, normalmente caracterizadas pela seleção adversa e o risco moral, e o grau de correlação do risco. Se segurar custa caro, mais caro custa não segurar. Essa é uma verdade que, hoje, já pode ser vislumbrada em números.

Até pouco tempo o custo dos eventos extremos recebia pouca atenção da mídia, seguradoras e poderes envolvidos, exceto após sua ocorrência. Esse pensamento foi se modificando nos últimos anos, quando países desenvolvidos e em desenvolvimento começaram a contabilizar os prejuízos do crescimento vertiginoso dessa espécie de evento, cujo auxílio ou resposta de emergência refletem diretamente no orçamento público e, indiretamente, no contribuinte.

\section{O CUSTO DOS EVENTOS EXTREMOS}

As seguradoras têm consciência de que devido às mudanças no clima os efeitos negativos futuros dos eventos extremos se tornarão ainda mais severos. De acordo com alerta recente da Suiss Re Group (2016): “[...] caso nenhuma medida seja tomada, as mudanças climáticas podem custar à economia mundial um valor estimado de 20\% do PIB global até o final deste século". Em 2017:

As perdas econômicas totais decorrentes de desastre em 2016 quase duplicaram, chegando a US $\$ 175$ bilhões, principalmente devido a catástrofes naturais. Isso mostra o quanto o mundo ainda não é resiliente o suficiente para evitar seus efeitos negativos - e muito menos para assegurar os fundos necessários para reconstruir comunidades afetadas após um desastre. (SWISS $\mathrm{RE}, 2016)$.

Dados disponibilizados pelo Swiss Re Group, no relatório Sigma n11/2018, informam que, também em 2017, o total de danos segurados causados por catástrofes naturais e antropogênicas 
de grande magnitude foram de 144 bilhões de dólares. A temporada de furacões no Atlântico Norte e uma série de incêndios florestais, tempestades e chuvas fortes em diferentes regiões levaram ao nível mais alto de perdas globais já registrado por catástrofe em um único ano. Os danos econômicos totais foram de 337 bilhões de dólares, gerando uma lacuna de proteção global contra catástrofes de 193.000 milhões de dólares em 2017. Em todo o mundo, mais de 11.000 pessoas perderam a vida ou desapareceram e milhões de ficaram sem casa. (SWISS RE, 2018).

O número de desastres, vítimas e perdas econômicas seguradas, no mundo, no ano de 2017, pode ser vislumbrado pela tabela que segue. Nela pode-se observar que a América Latina ocupa lugar de destaque em relação ao número de vítimas.

Tabela 1 - Desastres, vítimas e danos segurados em 2017.

\begin{tabular}{|c|c|c|c|c|c|c|c|}
\hline \multirow[b]{2}{*}{ Región } & \multirow[b]{2}{*}{ Número } & \multirow[b]{2}{*}{ Victimas } & \multirow[b]{2}{*}{ en $\%$} & \multicolumn{2}{|c|}{ Daños asegurados } & \multicolumn{2}{|c|}{ Daños económicos } \\
\hline & & & & $\begin{array}{r}\text { en miles de } \\
\text { millones de USD }\end{array}$ & en $\%$ & $\begin{array}{r}\text { en miles de } \\
\text { millones de USD }\end{array}$ & en $\%$ \\
\hline Norteamérica & 66 & 466 & $4.1 \%$ & 119.1 & $82.5 \%$ & 244.2 & $72.4 \%$ \\
\hline Latinoamérica y Caribe & 19 & 1375 & $12.1 \%$ & 5.1 & $3.5 \%$ & 31.6 & $9.4 \%$ \\
\hline Europa & 46 & 536 & $4.7 \%$ & 12.0 & $8.3 \%$ & 23.7 & $7.0 \%$ \\
\hline Africa & 40 & 2919 & $25.6 \%$ & 0.8 & $0.5 \%$ & 2.9 & $0.9 \%$ \\
\hline Asia & 112 & 5546 & $48.6 \%$ & 5.0 & $3.5 \%$ & 31.2 & $9.2 \%$ \\
\hline Oceania/Australia & 5 & 100 & $0.9 \%$ & 2.1 & $1.4 \%$ & 3.3 & $1.0 \%$ \\
\hline Mar/Espacio & 13 & 462 & $4.1 \%$ & 0.3 & $0.2 \%$ & 0.3 & $0.1 \%$ \\
\hline Mundo & 301 & 11404 & $100.0 \%$ & 144 & $100.0 \%$ & 337 & $100.0 \%$ \\
\hline
\end{tabular}

Nota: puede que algunos porcentajes no sumen 100 debido al redondeo.

Fonte: Swiss Re (2018, p. 7).

Os dados representam que a relação entre danos econômicos e assegurados é uma conexão muito mais real do que antigamente, porém, ainda insuficiente. De fato, o contrato de seguro não representa, isoladamente, uma solução para os custos gerados pelos eventos extremos, mas seu crescimento demonstra o potencial deste instrumento compensatório num contexto maior e em comparação com os demais instrumentos de compensação. O seguro tem a possibilidade de premiar, através de baixos prêmios, o indivíduo que investe em medidas de redução de risco, ao 
mesmo tempo em é responsável por pagar essa mesma pessoa pelos danos sofridos, caso o evento ocorra. (ROTH; KUNREUTHER, 1998). Essa característica revela também sua face preventiva, pouco reconhecida pela leitura clássica do instituto, mas absolutamente relevante para um círculo de gestão de riscos catastróficos.

Além do traço preventivo, as discussões em torno da segurabilidade dos eventos extremos têm contribuido para o debate em torno de duas "[...] questões fundamentais dos programas de gestão de risco, quais sejam: i) quem deve arcar com o custo para tornar as comunidades em áreas de risco seguras (?) e ii) quem deve pagar pelas perdas causadas por desastres (?)". (ROTH; KUNREUTHER, 1998, p. 2). O objetivo principal desses programas é a redução das perdas futuras, caso o evento se concretize.

Os critérios eficiência e equidade são normalmente utilizados como parâmetros iniciais para a resposta às perguntas i) e ii). O primeiro relaciona-se com a alocação de recursos econômicos para maximizar o bem-estar social. Esse, contudo, não é um critério tão simples quanto parece. A concepção de bem-estar social está vinculada à cidadania, cuja compreensão varia de uma entidade política para outra. Assim:

A sociedade que acredita que todos os cidadãos têm responsabilidade pelo pagamento das perdas das vítimas em caso de desastre, em geral, considera a tributação ferramenta política eficiente para a regeneração da receita a fim de cobrir tais custos. Por outro lado, a sociedade que crê que cada indivíduo é responsável por arcar com os encargos dos riscos que assume, pode considerar o seguro, com uma taxa variável baseada nos riscos, uma alternativa mais apropriada. (ROTH; KUNREUTHER, 1998, p. 3).

O critério equidade refere-se à preocupação com justiça e distribuição dos recursos. É fato que em matéria de desastre a distribuição de recursos demanda um especial tratamento de alguns indivíduos em relação a outros. Considerando a vulnerabilidade da maioria das comunidades em real situação de risco, essa distribuição não seria um problema, caso fosse pontua e esporádica, o que não tem sido a realidade. Ademais, nem sempre o que é considerado equitativo e justo logo após a ocorrência de um evento extremo, se revela eficiente a longo prazo. Por exemplo, a concessão de empréstimos e financiamentos a moradores de áreas de risco com o objetivo de torná-los capazes de recuperar suas moradias e permanecer nesses locais, não apenas incentiva o estabelecimento de mais pessoas naquele local, como sujeita o contribuinte ao aumento de altas despesas para assegurar as vítimas de futuros desastres. (ROTH; KUNREUTHER, 1998). 
Dada a complexidade engendrada pelos critérios da eficiência e equidade, entende-se que outros dois princípios são basilares para que o seguro desempenhe um papel mais significativo na gestão e no financiamento de riscos catastróficos. O primeiro deles é o de que i) os prêmios devem refletir os riscos. Esse princípio tem por finalidade fornecer aos indivíduos sinais precisos quanto à natureza dos riscos que enfrentam, e encorajá-los a adotar medidas de mitigação rentáveis para reduzir sua vulnerabilidade. Prêmios baseados em risco também refletem no custo do capital que as seguradoras precisam embutir em seus preços para assegurar um retorno adequado aos investidores.

Ocorre que isoladamente esse princípio não é adequado a todas as situações. Isso porque, caso venha a ser disponibilizado, nem todo cidadão terá condições de arcar com seu valor. Essa é a realidade de países como o Brasil. Por essa razão, um segundo princípio precisa ser levado em consideração, qual seja, ii) o enfrentamento da equidade e acessibilidade. A ponderação entre os princípios i) e ii) é o ideal, especialmente para não deixar desamparados os vulneráveis, que mais necessitam de auxílio frente ao cenário de riscos climáticos. Com o objetivo de oportunizar acessibilidade para quem mais precisa, alguns países têm desenvolvido programas de vouchers e incentivos, especialmente mediante parceria público/privada, conforme se verificará na sequência.

Por ora, além das limitações, muitos indícios apontam que o papel do seguro na compensação das vítimas de desastres extremos deve aumentar. Isto é evidenciado por diversos movimentos como: recentes negociações internacionais no âmbito da UNFCCC; iniciativas de muitos países em desenvolvimento no sentido de distribuírem seus riscos, o estabelecimento de novos mecanismos de seguros em países desenvolvidos, abrangendo, inclusive inundação, dentre outros eventos extremos. (LYSTER, 2015). Para compreender essa tendência, relevante proceder a um paralelo entre vantagens e obstáculos envolvendo a segurabilidade climática.

\section{VANTAGENS E OBSTÁCULOS DA SEGURABILIDADE CLIMÁTICA}

Boa parte da revisão da literatura (BOTZEN; VAN DEN BERGH, 2009; MILLS; LECOMTE, 2006) tem destacado que as seguradoras vislumbram a mudança climática como potencial oportunidade de negócios, razão pela qual também podem ser grandes parceiras na promoção da adaptação ao fenômeno. (HECHT, 2007).

Blazey e Govin (2007, p. 29) vão além e afirmam que "[...] mudança climática e seguro dependem um do outro, e as seguradoras desempenham grande papel na adaptação enquanto a 
adaptação auxilia que a indústria do seguro se mantenha viável". Esse raciocínio faz parte da escola que considera o seguro como valia para a implementação das medidas de controle e gestão de risco dos governos, tendo vista a influência que as seguradoras desempenham no comportamento de risco individual e organizacional. Neste sentido, o seguro é compreendido como um instrumento de incentivo e orientação de comportamento preventivo, (SURMINSKI; ORAMAS-DORTA 2014) não se limitando a desempenhar apenas um papel compensatório. Seria um mecanismo capaz de fornecer sinais de preços e comunicação de risco que influenciariam indivíduos, governos e empresas a reduzirem sua vulnerabilidade através de prevenção ou mitigação de perda. (LYSTER, 2015, p. 294).

Nesse sentido, em relação ao seguro contra inundações, por exemplo, as seguradoras poderiam estabelecer políticas diferentes para famílias e empresas que estão estabelecidas em áreas propensas a inundações. A variação de prêmios em classes de risco desincentiva o desenvolvimento em planícies inundáveis, o que pode reduzir indiretamente os riscos de inundação. Ou seja, incentivos para que os indivíduos limitem sua exposição ao risco, de modo que se tornem elegíveis para prêmios mais baixos podem contribuir para estimular a transparência e a consciência dos custos que uma área de risco traz.

Para Kunreuther (2008) Priest (1996), no entanto, o governo é um regulador superior às seguradoras quando se trata de regulação de risco, seja agindo pela via do zoneamento aprimorado, controle de uso da terra ou códigos de construção mais rígidos. De fato, há uma relação umbilical entre seguro para riscos catastróficos e política pública. Seguradoras precisam de uma efetiva estratégia governamental para se manterem solventes. Essa estratégia diz respeito ao engajamento da indústria de seguros com políticas públicas, o que também pode ser uma forma de auxiliar os governos a enfrentarem as consequências financeiras dos eventos extremos. A coleta de dados e informações confiáveis em nível local é uma das formas de intersecção entre política pública e indústria de seguros.

Assim, a fim de evitar o conhecido quadro do encolhimento do mercado segurador e o governo intervindo para reduzir os riscos e auxiliar nas ações pós-desastre (MILLS, 2009), seguradoras e poder público podem se unir para promover modificação de comportamentos. (BLAZEY; GOVIND, 2007). Por exemplo, a regulamentação pública em relação ás zonas de risco, emissão de gases do efeito estufa, remoção de pessoas de áreas de risco, e minimização do potencial de futuros danos representa grande incentivo para que as seguradoras assumas riscos de baixa probabilidade e alta magnitude em termo de consequências. (BLAZEY; GOVIND, 2007). 
Não obstante às possibilidades e vantagens apontadas para o seguro como mecanismo adequado para compensação de desastres, por uma variedade de razões, na prática, o mesmo é pouco utilizado. Além dos obstáculos mencionados para a materialização do seguro como mecanismo de compensação climática, pode-se observar que mesmo nos países onde seguros como o de inundação estão disponíveis no mercado, os indivíduos tendem a não contratar.

Algumas razões explicam essa postura: i) limitação cognitiva, eventos de baixa probabilidade como desastres "naturais" são sistematicamente mal avaliados, em geral resultando no pensamento "não acontecerá comigo ou não acontecerá de novo"; ii) auxílio governamental após a ocorrência do desastre pode ser um fator que reduz o incentivo para aquisição do seguro (RASCHKY, WECKHANNEMANN, 2007); iii) preferências por perdas incertas (SCHOEMAKER, KUNREUTHER, 1979); iv) informação ineficaz; v) o seguro é compreendido como um investimento que não traz retorno. (BRUGGEMAN, 2010).

Em relação à última justificativa, Kunreuther e Lyster (2017, p. 33) destacam uma realidade comum nos EUA.

A maioria dos proprietários em áreas propensas a inundações não adquire voluntariamente seguro contra inundações, mesmo quando é altamente subsidiado, ao menos até sofrerem danos [...]. Caso contratem, mas não experimentem perdas nos anos subsequentes, provavelmente cancelarão sua apólice.

Por isso, um dos grandes desafios das seguradoras é convencer os segurados de que o melhor retorno para um contrato de seguro é não ter nenhum retorno. (KUNREUTHER; LYSTER, 2016). Afinal, trata-se de uma atividade protetiva, não de um investimento. Esse desafio é maior do que parece, e seu grau de dificuldade passa despercebido, pois envolve comportamento. ${ }^{8}$ Logo, quem tem acesso ao seguro, tanto em termos de oferta, quando de acessibilidade, "[...] deve comemorar a ausência de perda durante um determinado período, ao invés de simplesmente cancelar a apólice pela ausência de uso". (KUNREUTHER; LYSTER, 2016, p. 35).

Existem dois caminhos na busca de tentar tornar o seguro um instrumento compensatório mais efetivo frente aos eventos extremos. Um segue uma a perspectiva de escolha do cidadão na contratação do seguro (perspectiva da discricionariedade); outra, defende a ideia do seguro compulsório.

Kydland e Prescott (1997) asseveram que uma política discricionária pode ser ideal, mas não resultar, necessariamente, em algo socialmente ótimo a longo prazo. Para os autores, a menos que 
os indivíduos sejam proibidos de se instalar e permanecer em área de inundação, por exemplo, será muito difícil, forçá-los a saírem de suas casas. Isso porque acreditam que caso não saiam, o poder público construirá barragens e diques como forma de proteção. De fato, isso acaba acontecendo, pois em geral o número de pessoas presentes nesses locais é grande. Por essa razão, no lugar de investimento em planos de contenção de inundação para manter grupos em áreas de risco, os autores argumentam que a saída são regras explícitas, que restrinjam o desenvolvimento nessas áreas, ao invés de dar às pessoas discricionariedade de escolha.

Kunreuther e Pauly (1997) são enfáticos ao se posicionam favoravelmente em relação ao seguro compulsório. Justificam-no como uma saída para a baixa demanda por seguros, e para os grandes problemas pós-desasastre, tanto para as vítimas, quanto para o governo. Em geral, os proprietários que sofrem danos graves não possuem recursos para reconstruir seus imóveis, e acabam recorrendo ao governo, que, em geral, e responde com uma resposta e assistência pósdesastre altamente dispendiosa, pouco estratégica e não compensatória. Para evitar grandes despesas ex post, a opção do seguro privado obrigatório com taxas baseadas em risco é apontada pelos autores como uma opção. Nesse sentido, de acordo com os autores "[...] é mais eficiente um programa público ex ante que garanta cobertura de perdas catastróficas e subsidie residentes de baixa renda (que não podem pagar a cobertura), do que uma resposta púbica que sequer pode ser denominada de programa público de auxílio ex-post". (2006, p. 101).

Van den Bergh e Faure (2006, p. 25) afirmam que "[...] a necessidade de criar um grupo de risco suficientemente grande para apaziguar, dentre outras questões, o problema de seleção adversa pode justificar a cláusula de vinculação". Nesse contexto, "[...] os argumentos da eficiência e da solidariedade são fortes para justificar a extensão compulsória dos contratos de seguro de propriedade, subscritos voluntariamente, para cobrir o risco de desastres "naturais"'. (VAN DEN BERGH; FAURE, 2006, p. 54).

A exceção de solidariedade foi desenvolvida pela jurisprudência do Tribunal de Justiça Europeu. Ou seja, do ponto de vista do bem-estar global, algumas regras podem ser motivadas por objetivos de solidariedade nacional. (VAN DEN BERGH; FAURE, 2006). E mais, é aceitável que, em função da hipossuficiência econômica demonstrada, alguns recebam um subsídio para o custeio do seguro. ${ }^{9}$ A compulsoriedade em matéria de seguro já é uma realidade na Europa.

\section{O EXEMPLO DA COMPULSORIEDADE}


Na França, a compensação das vítimas de desastres "naturais" faz parte de um sistema regulamentado e inclusivo que socializa o risco, disseminando o custo dos danos causados por desastres para toda a população. (BRUGGEMAN, 2010). Sua justificativa está no Preâmbulo da Constituição de 1946, que "[...] proclama a solidariedade e a igualdade de todos os franceses em suportar o fardo resultante das calamidades nacionais (§ 12)". (FRANÇA, 1946). O sistema de gerenciamento de desastre não impõe limitações à possibilidade de proposição de ação de responsabilidade civil contra o governo ou atores privados. ${ }^{10} \mathrm{Em}$ vez disso, está estruturado para desincentivá-la através do fornecimento de um seguro alternativo, que é menos caro e normativamente superior porque associado à solidariedade social. Importante ressaltar que o País possui um sistema de seguridade social robusto que cobre o custo do tratamento de danos físicos por desastre. (CANNARSA, 2006).

Como resposta às perdas sofridas em decorrência de desastres "naturais", em 1982, o País aprovou a Lei n. 82-600, "[...] relative à l'indemnisation des victimes de catastrophes naturelles". ${ }^{11}$ De acordo com esse sistema, a compra voluntária do seguro básico dos proprietários desencadeia a obrigação de pagar um prêmio adicional para o seguro contra perdas relacionadas a desastres naturais e interrupções de negócios. Há, assim, uma extensão de cobertura obrigatória de contratos de seguro de propriedade, subscritos voluntariamente. A cobertura suplementar para perda catastrófica é financiada através de um prêmio adicional de 12 por cento em todos os contratos de seguro de propriedade. A cobertura obrigatória é aplicada a todos os indivíduos segurados, independentemente de serem particularmente vulneráveis a catástrofes naturais. (VAN DEN BERGH; FAURE, 2006, p. 30).

O sistema denomina-se CAT/NAT, é uma criação do governo, mas concretizou-se pela participação de companhias de seguros, que no início relutaram em expor passivos potencialmente significativos em um mercado sobre o qual tinham informações limitadas. O convencimento das seguradoras pelo governo resultou da criação de uma companhia de resseguros financiada pelo Estado, a Caisse Centrale de Réassurance (CCR), que reassegura 50\% do risco de apólices de seguro contra desastres a uma taxa extremamente competitiva. O sistema é atraente para seguradoras privadas, que retêm $50 \%$ do risco e vendem os $50 \%$ restante para o CCR. O governo fornece ao CCR uma garantia financeira, intervindo para pagar o excesso de responsabilidade quando $90 \%$ das reservas do CCR estiverem esgotadas. (FELDMAN; FISH, 2015).

Os prêmios do seguro são uniformes, calculados como uma percentagem fixa do custo, independentemente dos fatores de risco do segurado. Para alguns, esse aspecto da política CAT/NAT 
pode ser incentivador do risco moral, em particular pela possibilidade de o valor da solidariedade ser minado por indivíduos que assumem riscos inadequados, sabendo da possibilidade de poderem espalhar suas perdas relacionadas com desastre à população em geral. (FELDMAN; FISH, 2015).

Essa observação parte do tradicional paradigma (BEN-SHAHAR; LOGUE, 2012) de que todo seguro cria risco moral. Essa afirmação brada que embora o seguro represente uma alternativa de alívio no pós-desastre, sua desvantagem é que ele diminui o incentivo do segurado no sentido de mitigar as perdas. Ora, ainda que em algumas configurações de contrato essa seja a realidade, partir desse pressuposto é uma ótima desculpa para evitar o enfrentamento da questão por meio dessa alternativa de compensação. Se exemplos de insucesso são possíveis, o oposto também pode ser verdadeiro e merece reflexão. Por exemplo, algumas cláusulas dos contratos, como incentivos à mitigação e outras obrigações, podem levar os contratantes não apenas a evitar o risco moral, mas a tomar precauções mais eficientes. (GOLDBERG, 2009).

O sistema CAT/NAT francês aplica essa lógica de raciocínio, incentivando a implementação de políticas de prevenção sob a forma de planos de prevenção de riscos (PPR). Os municípios acabam tendo duas razões principais ou incentivos para elaborar PPR(s) eficazes e efetivos. A falta de criação de um PPR expõe os municípios às ações de responsabilidade civil. Em segundo lugar, também permite que o governo aumente a franquia na política CAT/NAT após a declaração de desastre "naturais" (esse valor não é fixo).

O exemplo francês de uma cobertura abrangente obrigatória foi seguido recentemente pela Bélgica, que regulamentou a extensão obrigatória para desastres "naturais" (inundações, terremotos, e deslizamento de terra) da cobertura de seguro de incêndio adquirida voluntariamente para os chamados riscos simples. A diferença da Bélgica para o sistema da França é que a seguradora pode investigar o risco para cada caso individual e ajustar o prêmio em conformidade. Logo, o prêmio final será diferente em função do risco real. (FAURE; HARTLIEF, 2006).

Apesar de muito interessante, a diferença de realidade da França, Bélgica e Brasil não podem ser desconsiderada. Ademais, a criação de um sistema como o exemplificado demandaria estruturas que não seriam facilmente adaptáveis em países em desenvolvimento. Nesse sentido, importante refletir acerca de alternativas que potencializem a solvência das seguradoras. O resseguro e a transferência de riscos são dois exemplos bastante desenvolvidos na atualidade. 


\section{Resseguro a Alternativa da Transferência de Risco no Mercado de Capitais}

Conforme destacado, desastres demandam reconstrução, que necessita de dinheiro, o que remete ao seguro, que enfrenta problemas tanto de demanda quanto de oferta. Em diversos casos, especialmente nos casos de eventos catastróficos, as perdas esperadas em geral excedem a capacidade de um segurador individual. Para evitar essa realidade, existem dois mecanismos para aumentar a capacidade da seguradora: o resseguro (que é o seguro das seguradoras) e a transferência de riscos para o mercado de capitais.

Em países desenvolvidos, o mercado de resseguros é um dos setores financeiros mais importantes, pois possibilita que as empresas tenham cobertura securitária para os bens já existentes e para a construção de obras de infraestrutura, necessárias para o desenvolvimento de uma nação.

O grande crescimento do setor no Brasil ocorreu a partir de 2008, com o fim do monopólio estatal sobre as operações de resseguro no Brasil. Segundo a Superintendência de Seguros Privados (Susep), o volume de prêmio cedido às resseguradoras atingiu 8,6 bilhões de reais em 2016, crescimento de $1 \%$ em relação aos 8,5 bilhões de reais registrados no ano anterior. ${ }^{12}$

Todavia, o resseguro pode ser insuficiente para fornecer a capacidade necessária e cobrir catástrofes de baixa probabilidade e alto risco (como um furacão de categoria 5, por exemplo). Nos EUA tem-se observado uma realidade onde não raras vezes, após anos catastróficos, o mercado de risco secundário trata as seguradoras primárias da mesma forma que essas tratam os clientes de seguros de propriedade, aumentando os preços e diminuindo a cobertura. (BERGHMAN, 2013). Na sequência de desastres significativos, a demanda do seguro de propriedades é alta, mas as seguradoras primárias não podem arriscar mais. Como consequência, se voltam para as resseguradoras, a fim de criar uma capacidade de subscrição adicional, mas o capital do mercado secundário também foi drenado, deixando as resseguradoras indisponíveis para renovar políticas antigas ou satisfazer novas demandas. Infelizmente, os custos acabam sendo transferidos para o consumidor e os preços aumentam. Por certo, essa realidade não perdura para sempre, mas em geral por um período, até que o mercado se reestabeleça do desastre.

Por essa razão, novas fontes de capital são fundamentais para facilitar o ciclo. Na última década, os mercados de capitais têm demostrado interesse e capacidade para assumir riscos catastróficos.

A natureza cíclica do mercado de resseguros faz com que as seguradoras primárias elevem os prêmios ou se retirem completamente dos riscos de 
subscrição em áreas propensas a catástrofes. Os mercados de capitais, por sua vez, representam uma solução potencial para essa falta de capacidade, e a maturidade do mercado de títulos (cat bonds) indica que eles podem ser a melhor solução. (BERGHMAN, 2013, p. 27).

Essas novas fontes de capital fazem parte do mecanismo denominado transferência alternativa de riscos, que aumenta a capacidade de securitização do risco. (BERGHMAN, 2013). Este mercado existe para proporcionar capacidade extra às seguradoras primárias. Usando vários métodos, essas entidades assumem segmentos dos riscos, subscrevem mais políticas, ao mesmo tempo em que estabilizam os preços.

Os títulos de catástrofe (também conhecidos catastrophe bonds) transferem um conjunto específico de riscos de um patrocinador para investidores. Foram criados e utilizados pela primeira vez em meados da década de 1990, no rescaldo do furacão Andrew e do terremoto de Northridge. Por esse mecanismo, investidores adquirem um título, cujo capital é perdido quando o parâmetro determinado pelo contrato for desencadeado.

Por exemplo, quando um furacão de categoria cinco atingir uma determinada cidade e causar pelo menos 15 bilhões em danos, imediatamente as obrigações assumidas pela aquisição do título vinculado ao risco estarão em vigor. Nos casos em que o evento (probabilisticamente baixo) ocorrer, o valor investido será utilizado para pagar as reivindicações de seguros. (BERGHMAN, 2013, p. 223). Essa é uma solução que também pode ser pensada para os casos de inundação.

A transferência de risco é uma opção que representa a convergência dos mercados de seguros e de capitais. Mercados tradicionalmente separados trabalhando em conjunto para desenvolver produtos que permitam espalhar e transferir o risco sobre a imensa capacidade dos mercados financeiros. (BERGHMAN, 2013). As catastrophe bonds estão mais próximas da transferência de risco pura, pois caso uma obrigação seja desencadeada, a próxima não será mais cara devido à capacidade substancialmente maiores dos mercados de capitais. (BERGHMAN, 2013).

\section{ALTERNATIVAS DE SEGURO PARA PAÍSES EM DESENVOLVIMENTO}

Como bem colocam Freeman e Kunreuther (2002, p. 211) 
[...] uma distinção primária entre países desenvolvidos e em desenvolvimento é o papel integral que a transferência de risco desempenha na gestão de risco. Em muitos países desenvolvidos, a transferência de risco é um componente de integração de estratégias variadas de gerenciamento de risco. Na maioria dos países em desenvolvimento, em geral, a transferência de risco não é um componente de uma estratégia abrangente.

Além disso,

[...] há uma distinção fundamental entre formas de transferir riscos de desastres 'naturais' entre países desenvolvidos e economias emergentes. $\mathrm{Na}$ maioria dos países desenvolvidos, o seguro é a principal forma de transferir o risco. Na maioria dos países emergentes ou em desenvolvimento, o governo compromete-se a financiar a reconstrução após um desastre. (FREEMAN; KUNREUTHER, 2002, p. 202).

Eventos extremos de início repentino são um problema crônico, especialmente para países em desenvolvimento. Embora as catástrofes climáticas estejam minando capacidades, nesses países os mecanismos de compensação são altamente inadequados, e os governos geralmente não têm recursos e vontade política de se envolver em um planejamento de longo prazo. Ademais, esse planejamento envolve questões urbanísticas, instituição ou readequação de códigos de construção, reassentamento e deslocamento, com vistas a reduzir a exposição a eventos climáticos extremos. (LYSTER, 2015).

Uma inundação pode ter consequências devastadoras para o processo de desenvolvimento econômico de um país ou estado, e ser um dos responsáveis por manter a população na pobreza. Daí surge a questão de saber como, mais particularmente, para o caso dos países em desenvolvimento, uma compensação adequada e efetiva pode ser fornecida às vítimas. Muitos diriam que não existe nenhuma resposta adequada, pois a melhor maneira de proteger a vítima é obviamente prevenção. Por certo, a prevenção sempre relevante. No entanto, é preciso lembrar que a prevenção, muitas vezes, baseia-se em uma cultura de gestão de risco, raciocínio de longo prazo, e no pressuposto de que o indivíduo tem várias opções de escolha e, portanto, podem optar pelo menos arriscado (se estabelecendo em uma área segura e construindo uma casa em uma área propensa a inundações). Infelizmente, essa não é a realidade das populações em países em desenvolvimento. (FAURE; WIBISANA, 2013). 
Nos EUA e na Europa há uma tendência de crescimento da compensação baseada em seguro complementada por parceria público-privada com apoio governamental (geralmente atuando como ressegurador) para fornecer resseguro onde os mercados falharem. (MICHEL-KERJAN; MARCELLISWARIN, 2006). Estes acordos são desenvolvidos principalmente para perdas de propriedade (casas) ou econômicas e não para danos pessoais ou danos à saúde, sendo estes últimos regidos pelo sistema de seguridade social. Ainda que alguns países europeus e os EUA tenham exemplos interessantes de compensação por meio do seguro, há que se ter em conta que sua aplicabilidade em países em desenvolvimento não é tão simples. Um esquema de seguro abrangente (obrigatório, como é o caso da França, por exemplo) pode gerar custos adicionais, e as necessidades e prioridades de indivíduos em países em desenvolvimento são muito diversas do mundo desenvolvido. Além disso, um esquema de seguro abrangente requer uma estrutura administrativa para geri-lo, que pode não estar em vigor em todos os países em desenvolvimento. Especialmente para indivíduos de baixa renda, mesmo que a informação sobre os riscos esteja disponível (o que não é a regra) muitas vezes alternativas simplesmente não estão sempre disponíveis à população. (LINNEROOTH-BAYER; MECHLER; HOCHRAINER-STIGLER, 2011).

Em geral, países em desenvolvimento e seus estados têm as dificuldades cotidianas agravadas na sequência do desastre porque as rendas que já são baixas diminuem, as reservas ficam exauridas, e o declínio de crédito dificulta empréstimos. A situação comumente é resolvida pelo desvio de valores orçados para outras finalidades ou por empréstimo do mercado interno e instituições financeiras internacionais.

Tendo em vista a necessidade de mudar essa realidade, programas de seguros recentes e inovadores representam alternativas para os países em desenvolvimento. Alguns exemplos serão analisados na sequência.

O SISTEMA DE MICROSSEGUROS E OS EXEMPLOS DO CARIBBEAN CATASTROPHIC RISK INSURANCE FACILITY ("CCRIF"), AFRICAN RISK CAPACITY E UP LOAN PROGRAM CT SHORE

O sistema de microsseguros é um exemplo de programa que fornece cobertura de baixo custo para famílias de pouca renda e empresas de pequeno porte, ao mesmo tempo em que oferta cobertura para aqueles que não podem pagar prêmios baseados em risco. "Serve para resolver o problema da assessibilidade". (FAURE, M. G.; FAURE, M.; WIBISANA, 2013, p. 269). Para expandir 
essa alternativa, o desafio é criar sistemas público-privados, apoiados por expertise e capital internacional, que possam sustentar eventos de grande magnitude.

O sistema baseia-se em índice (é paramétrico). Enquanto o seguro convencional é subscrito contra perdas reais, o seguro paramétrico é baseado em índice e é subscrito frente a gatilhos físicos ou econômicos. (LINNEROOTH-BAYER; MECHLER; HOCHRAINER-STIGLER, 2011). Tradicionalmente, as seguradoras pagaram créditos com base em perdas reais (seguro baseado em indenização) o que exige extensas redes de peritos que avaliam perdas individuais após um evento. Isso faz com que programas tradicionais de seguro, como de colheitas, sejam dispendiosos e demorados para segurado e segurador. Para evitar os altos custos de transação dos sistemas de seguro baseados em indenizações, os esquemas baseados em índice ou paramétricos fazem com que os pagamentos dependam de um gatilho físico, como a precipitação mensurada em uma estação meteorológica regional, o que evita liquidações caras e demoradas. Desse modo, no caso de derivados do clima, os agricultores têm acesso ao pagamento do seguro se o índice atingir uma certa medida, independentemente das perdas reais.

Esses esquemas podem oferecer uma alternativa menos onerosa e, portanto, mais viável à cultura tradicional baseada em indenização. Essa espécie de seguro já está à disposição para agricultura e pecuária em países como Malawi e Mongólia, respectivamente. Apesar de inovador, e com potencial de aplicabilidade até para casos de inundação, seu sucesso depende da capacidade de pagamento das coberturas necessárias, do apoio de assistência técnica, de subsídios nacionais ou de doadores internacionais. (LINNEROOTH-BAYER; MECHLER; HOCHRAINER-STIGLER, 2011).

À luz dos custos significativos que envolvem os eventos extremos, outro desafio é identificar camadas apropriadas de transferência de risco com custos mais baixos. (LINNEROOTH-BAYER; MECHLER; HOCHRAINER-STIGLER, 2011). A palavra camada aqui possui exatamente a noção de reforço em diferentes níveis. O CCRIF (CARIBBEAN CATASTROPHE RISK INSURANCE FACILITY) ${ }^{13}$ é o primeiro esquema de pool de risco entre estados do mundo nesses moldes e possui vários recursos inovadores. O CCRIF funciona como uma companhia de seguros controlada pelos governos participantes. Oferece seguro de catástrofe menos oneroso do que o disponibilizado através de mercados comerciais de seguros e resseguros. Embora interaja com os atores do setor privado nos mercados de seguros e resseguros comerciais, os representantes governamentais contribuem para o funcionamento do esquema, garantindo assim que a tomada de decisões reflita as necessidades dos Estados membros. Ao reunir o risco de nível regional, os países do Caribe podem evitar ter que reservar grandes quantidades de dinheiro público para atender ao risco de um ciclone ou terremoto 
tropical catastrófico. O pool de riscos ${ }^{14}$ em nível regional proporciona eficiência na administração do seguro. Ao invés de cada estado ter uma administração separada do seguro de risco catastrófico, esta função é centralizada a nível regional através do CCRIF. (MCGEE et al., 2014). O CCRIF cobre uma pequena proporção das reivindicações potenciais através de contribuições dos Estados membros e compra cobertura de resseguro nos mercados de resseguros internacionais para cobrir reivindicações até determinado nível no ano.

A cobertura do seguro baseia-se em no mecanismo de gatilho paramétrico. O valor a ser pago ao abrigo do seguro é predeterminado por um modelo de estimativa de perdas que identifica o valor devido ao estado segurado após um ciclone tropical ou um terremoto de particular gravidade, por exemplo. O CCRIF é, portanto, capaz de distribuir rapidamente dinheiro para os estados afetados e evitar atrasos que por vezes ocorrem nas políticas de danos de propriedade indenizáveis disponíveis nos mercados de seguros comerciais. Sua capitalização inicial proveio do financiamento de países desenvolvidos e organizações internacionais de fora da região do Caribe. (MCGEE et al., 2014).

Embora esse sistema represente um modelo instrutivo como mecanismo de transferência de risco regional para uma maior adaptação aos eventos climáticos extremos relacionados com mudanças climáticas, possui uma desvantagem. As perdas financeiras sofridas como resultado do evento catastrófico podem diferir do valor calculado de acordo com o modelo de estimativa de perda, deixando os estados membros com uma queda na cobertura. Ainda assim, os segurados têm assumido esse tipo de risco para garantir o acesso rápido aos fundos, visto que nessas circunstâncias é difícil avaliar com precisão a perda real associada a um evento climático extremo. (MCGEE et al., 2014).

O pool de riscos pode dispersar riscos entre regiões, grupos regionais, nacionais e até internacionais. Entre os setores público e privado pode reduzir consideravelmente o custo do risco. O desafio, contudo, é desenvolver procedimentos unificados de estimativa e "cultura de risco" comum para as regiões e países envolvidos, (LINNEROOTH-BAYER; MECHLER; HOCHRAINER-STIGLER, 2011), bem como identificar características de exposição e vulnerabilidade semelhantes.

O Caribbean Catastrophic Risk Insurance Facility ("CCRIF")15 e o African Risk Capacity, (2016) são dois exemplos de como configurar um esquema e conceber limites objetivos hidrológicos e meteorológicos que desencadeiem pagamentos de seguros. A ideia de um pool de risco nesses programas baseia-se no fato de que as secas ou inundações não acontecem em todos os anos nas 
mesmas partes do continente e, portanto, nem todos os países que participam no pool receberão um pagamento.

Uma alternativa para manter os prêmios baseados em risco, sem desconsiderar acessibilidade, é a concessão de valores que cubram parte do custo do seguro, ou empréstimos para investimento em mitigação. Por exemplo, o departamento de Habitação de Connecticut, nos EUA, desenvolveu o programa "Up Loan Program CT Shore", ${ }^{16}$ voltado para residências unifamiliares próprias, alugadas e empresas. O financiamento tem por objetivo aprimorar elevações das propriedades e facilitar adaptações relacionadas às atividades de proteção contra inundações e vento. O valor do voucher (valor concedido pelo programa) é determinado pelo rendimento da família e a magnitude do aumento do prêmio do seguro. (KUNREUTHER; MICHEL-KERJAN, 2013).

A parceria público-privada também é uma alternativa. Como resultado das últimas enchentes no país e décadas de negociação, em 2014, o governo Britânico e a Associação Britânica de Seguradores fecharam um acordo cujo objetivo é estabelecer um equilíbrio entre governo e o setor privado de seguro, diante das mudanças climáticas e desastres relacionados ao clima. As tratativas receberam autoridade estatutária nos termos da Parte 4 do Water Act $2014^{17}$ e vigerão por 25 anos, expirando em 2039. Resumidamente, os principais pontos do acordo são: oferta de seguro em áreas de alto risco com preços acessíveis; estabelecimento de um esquema de resseguro para inundação Flood Reinsurance Scheme (Flood Re), com o propósito de proporcionar disponibilidade e acessibilidade para as moradias, bem como gerenciar a transição do preço relacionado ao risco do seguro contra inundações ao longo de um período de 25 anos para as famílias; garantia de que o governo será o primeiro responsável pelas perdas em caso de um evento catastrófico que o esquema de resseguro não possa arcar; e a assunção de responsabilidade por parte do governo de aumentar os gastos com medidas de proteção contra a inundação.

O exemplo inglês é inovador e pode oferecer insights e inspiração para outras jurisdições em busca de um equilíbrio entre o público e o privado diante dos desastres "naturais" e a compensação das vítimas. Contudo, a existência de alternativas ligando seguro a eventos extremos não é suficiente para apagar as diferenças de realidades, vulnerabilidades, culturas e economias. Não há uma fórmula de seguro aplicável a desastres. Ademais, é improvável que os prêmios possam refletir adequadamente o risco de catástrofes climáticas extremas ou que a equidade e a acessibilidade possam ser resolvidas no curto prazo nos países em desenvolvimento. Por essa razão, governos, agências multilaterais e países doadores serão fundamentais para estabelecer iniciativas de pool de 
riscos catastróficos e esquemas de micro seguro de pequena escala, alternativas capazes de entregar uma espécie de alívio às vítimas frente às d do seguro. (KUNREUTHER; LYSTER, 2016).

\section{CONCLUSÃO}

Para que o seguro possa ser um instrumento de compensação contributivo num contexto compensatório de vítimas de eventos extremos, inicialmente, há que se superar o raciocínio excludente de que eventos relacionados com o clima não são seguráveis. Em um segundo momento, as disposições contratuais são de grande importância, posto que podem controlar e motivar comportamentos do segurado com o objetivo de evitar e minimizar a ocorrência de perdas.

No Brasil a hipótese de uma releitura do contrato de seguro a fim de incluir os eventos climáticos correlatos com o clima está absolutamente respaldada pelo princípio da função social, acolhido expressamente pelo Código Civil (artigos 421 e 1.228, § 1.ํ), "[...] que constitui, em termos gerais, a expressão da socialidade no Direito Privado, seguindo a diretriz constitucional da solidariedade social" (CF, art. 3.․, III, in fine). Há que se ter em conta que o direito contratual da atualidade se situa em num quadro de referências principiológicas. Disso decorre a autonomia privada solidária, força estruturante de uma nova dogmática contratual, que é oriunda da conjugação ou entrelaçamento entre as ideias-chave da liberdade de contratar e função social do contrato.

Nesse sentido, "a segurabilidade deve ser compreendida como um conceito fundamental, mas variável". (FAURE; HE, 2017, p. 6). De fato, se comparados a outros riscos, o climático é sui generes por sua associação a uma considerável incerteza. Todavia, com o desenvolvimento das bases de dados e dos modelos climáticos, torna-se cada vez mais possível identificá-lo e quantificá-lo, afastando-o da linha do risco de alta incerteza.

Acerca da variabilidade, pode-se dizer que aquilo que hoje não é segurável, logo na sequência pode se tornar, por exemplo, pela evolução da tecnologia, que permita maior informação acerca do risco. Ademais, três fatores são considerados na verificação da segurabilidade ou não dos riscos de catástrofe relacionados ao tempo: a previsibilidade do risco, a perda potencial no caso de o risco se materializar, e a aleatoriedade do risco. Tendo em consideração esses fatores, e mais alguns a depender da especificidade de cada país ou região (vulnerabilidade local), existem diferentes políticas de seguro para cobrir desastres relacionados com o clima no mundo. No Brasil essa não é uma realidade, especialmente em termos urbanos, o que acaba sendo mais um fator de 
gastos públicos extraordinários que, de nenhuma forma contribuem para uma gestão de risco do próximo evento de forma preventiva.

O seguro é relevante porque tem a capacidade de aglutinar prevenção e compensação. Ainda que sua principal atuação apareça no pós-desastre, para que as seguradoras incluam os eventos extremos em seu portfólio, e não apenas entrem no mercado, mas nele permaneçam, uma postura de gestão de risco é absolutamente fundamental. Compreender essa relação circular proativa talvez seja o primeiro passo num processo de superação de uma série de obstáculos, que não são apenas normativos, mas políticos e sociais.

Ademais, é importante definir com que objetivo se pensa no seguro. Se o intuito for tornálo um instrumento compensatório, capaz de desempenhar um papel significativo na gestão e financiamento de risco de desastres (eventos extremos de baixa probabilidade e grandes consequências), alguns princípios precisam ser observados: i) os prêmios devem refletir os riscos; ii) a premissa do valor dos prêmios não deve perder de vista questões como justiça e acessibilidade.

Sem a atenta observação do binômio prêmio (risco verdadeiro) x acessibilidade, a estrutura de seguro, especialmente, para inundação (uma das necessidades brasileiras) nasce fadada ao insucesso. Além disso, o setor público também pode desempenhar seu papel, fornecendo proteção contra perdas catastróficas que não podem ser cobertas pelo setor privado, o que representa uma alternativa à solvência da seguradora. Ressalta-se nesse caso, o poder público não é o primeiro a ter que agir.

Assim, o seguro é um elemento vital da política de gestão de risco frente a eventos extremos, bem como, de uma estrutura compensatória. Representa "importante ferramenta para cobrir os desastres climáticos devido à sua expertise em gerenciamento de riscos." (FAURE, 2017, p. 5)

Todavia, ao ser projetado, precisa levar em consideração a disseminação dos riscos entre os atores, locais, tempo, e assegurar fundos disponíveis para cobertura das perdas. Essa medida também é conhecida como programa de seguro contra desastres multicamadas (multi-layer disaster insurance program - MLDIP). Um MLDIP requer a análise de exposições de risco das partes interessadas envolvidas. Por exemplo, se uma seguradora necessita diminuir as chances de insolvência, poderá trabalhar com prêmios mais altos, diminuindo a cobertura, mas, também, poderá contratar resseguro e comprar título de catástrofe. Nesse caso, o ônus das perdas é deslocado para longe da seguradora, sendo redistribuído de forma equilibrada entre outras partes interessadas. Caso contrário, pode levar à instabilidade ou ruína. Assim, o sucesso de um programa de compartilhamento de perdas depende da estabilidade mútua (sistêmica) dos stakeholders 
heterogêneos envolvidos. Um programa de seguro contra desastres multicamadas (MLDIP) na forma de uma parceria público-privada (PPP) pode incluir, por exemplo, uma camada de seguro privado, uma camada de transferência de risco através de resseguro ou créditos de catástrofe, e uma camada de contribuição do governo.

Esse conjunto de camadas justifica-se, especialmente, se o intuito for desenvolver um programa de seguro para inundações, por exemplo. Há, sem dúvidas, um lado escuro na estimativa na busca por estimativas de riscos desses eventos. $O$ fato de estarem ligadas à mudança climática e às mudanças hidrológicas são duas razões para essa obscuridade. Com relação à primeira razão, muitas estimativas baseiam-se na experiência histórica, assumindo que os riscos de inundação são estáveis ao longo do tempo. Ocorre que a mudança climática vai aumentar a probabilidade de inundações em muitas áreas, então é importante ter em mente que as estimativas são tendenciosas para baixo. Os riscos de inundação também podem mudar devido a mudanças no uso da terra. Isso envolve a destruição de importantes sumidouros naturais que ajudam a controlar as inundações; a existência de superfícies impermeáveis, que também aumentam os riscos de inundação, porque a água é liberada mais rapidamente, dentre outros. O ajuste desses fatores é complicado e gera incertezas porque não se pode prever, com precisão, o futuro desenvolvimento urbano. 0 apontamento dessas questões não tem o condão de ignorar as estimativas existentes, ou argumentar contrariamente a hipótese do seguro para inundação. Ao contrário, tem o objetivo de salientar o que se tenha é um melhor julgamento profissional, não um número cientificamente preciso. "Há que se ter em mente que os fatores mencionados levam a subestimações sistemáticas de risco. Essa é uma boa razão para adicionar uma margem significativa de segurança, ou, em outras palavras, para adotar uma abordagem precaucional no gerenciamento dos riscos de inundação". (FARBER, 2017)

Em resumo, devido às interdependências significativas entre perdas catastróficas em diferentes locais, a demanda por um determinado instrumento financeiro não pode ser separada da demanda por outras medidas de transferência e redução de risco. Nesse sentido, uma das direções futuras para a abordagem denominada gestão integrada de risco de catástrofe ICRM (integrated catastrophe risk management) seria considerar uma escolha combinada de medidas de compartilhamento de perdas financeiras entre as partes interessadas e medidas estruturais de mitigação de inundações (tais como zoneamento de certas áreas, elevação de áreas ou edifícios particulares, impermeabilização de outras, etc). 
Os exemplos do sistema de pool de risco, de microsseguro e dos vouchers tmbém são relevantes para se pensar numa estratégia brasileira. O pool de riscos (aqui possui um sentido diferente daquele utilizado na responsabilidade civil) parece especialmente relevante porque pode dispersar riscos entre regiões, grupos regionais, nacionais e até internacionais. Entre os setores público e privado pode reduzir consideravelmente o custo do risco. O desafio, contudo, é desenvolver procedimentos unificados de estimativa de risco e uma cultura de risco comum para as regiões e países envolvidos. Quando mais abrangente ou global, maior a chance de os impactos de desastres serem compensados por um grande número de atores. Por exemplo, danos em Xangai podem ser compensados por riscos em uma megacidade, como Londres, que está geograficamente distante dos danos originais. O agrupamento de riscos entre cidades de países ou estados diferentes, mas com características de exposição e vulnerabilidade semelhantes parece especialmente apropriado para eventos de baixa probabilidade e alta magnitude. A ideia de um pool de risco baseiase no fato de que as secas ou inundações não acontecem em todos os anos nas mesmas partes do continente e, portanto, nem todos os países que participam no pool receberão um pagamento.

Um dos maiores exemplos de atuação do poder público em matéria de inundação no mundo é o Programa Nacional de Seguro de Inundação (NFIP - National Flood Insurance Program). Atualmente o programa encontra-se em dificuldades devido a uma dívida com o tesouro, uma das razões pelas quais passa por uma fase de revisão. Alvo de inúmeras críticas, a questão mais séria desse esquema é o fato de subsídios não condizerem com a realidade dos riscos dos segurados. Esse ponto, portanto, deve ser observado como algo que não deve ser feito.

Todavia, algumas propostas (MICHEL-KERJAN, 2011), atualmente em estudo nos EUA, para redesenhar o programa, servem de base inspiradora para a estruturação de um sistema de compensação por inundação no Brasil, a partir do seguro. Para tanto, alguns objetivos precisam ser implementados simultaneamente, porque complementares. Primeiro, diante do comportamento míope da maioria das pessoas expostas a áreas de risco, o seguro de inundação deve ser vendido por contratos plurianuais (por exemplo, 5 ou 10 anos) fixados diretamente na matrícula do imóvel em risco e não vinculados ao proprietário. Essa medida evitaria o cancelamento do seguro depois de apenas um ano e, caso o proprietário decida mudar para outro local, o contrato seria transferido para o novo proprietário. Como resultado, muitas mais propriedades serão cobertas e permanecerão assim ao longo do tempo. Segundo, os prêmios devem ser baseados em risco para todos, de modo que os proprietários serão informados da verdadeira exposição de sua residência a danos potenciais de inundação. Um programa de vouchers de seguro de inundação, levando em consideração 
questões de equidade e acessibilidade, para complementar a estratégia de prêmios baseados em risco para todos. Os proprietários que residem atualmente numa zona de alto risco e necessitem de tratamento especial receberiam um voucher do programa. Terceiro, os contratos de seguro poderiam ser complementados com empréstimos concedidos pelo governo ou pelos bancos com vistas a encorajar o investimento em medidas de redução de risco. Quarto, redução da exposição ao desastre, por meio da compra de resseguro privado e títulos de catástrofe. Quinto, em troca do seguro subsidiado as comunidades devem proteger as novas construções, melhorar e reforçar estruturas, adotando assim as regulações correlatas às planícies de inundações. A obrigação até pode ser voluntária, mas o programa precisa prever que se uma determinada comunidade escolher não participar do processo, a mesma será mapeada e suspensa do programa, não podendo em decorrência disso, receber assistência de reparação e construção em caso de inundação.

Como se pode observar, potencialidades existem, mas as limitações também são consideráveis. Nessa linha, a aderência à noção compensatória, tendo como instrumento o seguro ou outro, está conjugada com uma série de medidas, que não são apenas jurídicas, mas econômicas, culturais e, em última medida, psicológicas (comportamentais). Logo, uma estratégia que pretenda obter sucesso em termos de gestão e transferência de risco precisa atentar para essas questões diversas que, ao fim refletem no Direito.

O seguro climático não é utópico, mas pensar que o mercado segurador irá, sozinho, assumir riscos como os que mais vulnerabilizam nosso País, é utopia. Experiências de países que já enfrentaram e ainda vivenciam grandes inundações (como é o caso do EUA e de alguns países da Europa) demonstram que se o intuito é desenvolver o seguro como um instrumento compensatório, um planejamento que envolve diversos parceiros, com destaque para a parceria público-privada, é um passo a ser considerado.

\section{NOTAS EXPLICATIVAS}

1 Os termos desastres e catástrofes serão utilizados como sinônimos. As aspas no termo "naturais" justifica-se pelo fato de que, ainda que parcialmente, há comprovação científica de da participação humana no processo da mudança no clima.

3 "A seleção adversa se manifesta quando os indivíduos de alto risco têm mais probabilidade de necessitar da cobertura do seguro que as pessoas de baixo risco. É causada por assimetrias de informações entre empresas de seguros e segurados. Esse problema pode surgir quando os indivíduos são capazes de determinar suas características de risco individuais e as companhias de 
seguros têm dificuldades em distinguir os bons dos maus riscos". (BOTZEN; VAN DEN BERGH, 2008, p. 419).

${ }^{4} \mathrm{O}$ conceito de risco moral está ligado a "um aumento nas perdas esperadas (probabilidade ou quantidade de perda condicional em um evento) causado por mudanças no comportamento do segurado". (KUNREUTHER; MICHEL-KERJAN, 2007, p. 1825).

5 Apenas a título explicativo, e dado o caráter interdisciplinar do seguro em matéria climática, importante destacar que enchente, inundação, alagamento e deslizamento são coisas diferentes. Inundação representa o transbordamento das águas de um curso d'água, atingindo a planície de inundação ou área de várzea. As enchentes ou cheias são definidas pela elevação do nível d'água no canal de drenagem devido ao aumento da vazão, atingindo a cota máxima do canal, porém, sem extravasar. O alagamento é um acúmulo momentâneo de águas em determinados locais por deficiência no sistema de drenagem. Além das inundações bruscas e os processos geológicos correlatos, a Lei no 12.608 de 2012, em seu artigo 6으, VII, menciona as "áreas suscetíveis à ocorrência de deslizamentos de grande impacto". Esse, também conhecidos como movimento de massa, escorregamento, ruptura de talude, queda de barreiras, entre outros, se refere aos movimentos de descida de solos e rochas sob o efeito da gravidade, geralmente potencializado pela ação da água. (BRASIL, 2012; SÃO BERNARDO DO CAMPO, 2011).

6 Planície protegida por diques contra inundações.

7 De acordo com o IPCC, em termos estatísticos, um evento climático extremo é aquele no qual o valor da variável (por exemplo, temperatura) se situa muito próximo dos valores mais baixos ou mais elevados ou além desses limites - o que se observa ao longo de décadas. Esses extremos poderão ser considerados um desastre climático a depender de sua magnitude, vulnerabilidade da região, e exposição da comunidade impactada. (ALLEN et al., 2012, p. 5).

8 Pesquisas da área da psicologia cognitiva e decisões comportamentais nos últimos 30 anos revelaram que indivíduos e organizações geralmente tomam decisões sob condições de risco e incerteza combinando pensamento intuitivos e deliberativos. No livro Thinking, Fast and Slow o Prêmio Nobel Daniel Kahneman caracterizou as diferenças entre esses dois modos de pensando. O pensamento intuitivo (Sistema 1) opera de forma automática e rápida com pouco ou nenhum esforço e nenhum controle voluntário. Muitas vezes, é guiado por reações emocionais e regras que foram adquiridas por experiência pessoal. O pensamento deliberativo (Sistema 2) aloca a atenção para atividades mentais atentas e intencionais, onde as pessoas realizam compras (negócios ou tomam decisões) reconhecendo as interdependências relevantes e a necessidade de 
coordenação. As escolhas são normalmente feitas combinando os dois modos de pensamento e geralmente resultam em boas decisões quando os indivíduos têm uma experiência passada considerável como base para suas ações. "No que diz respeito aos eventos de baixa probabilidade e alta magnitude (LP-HC), no entanto, há uma tendência de ignorar um desastre potencial ou exagerar devido a uma recente, o que pode fazer com que as decisões possam não refletir avaliações de risco". (KAHNEMAN, 2013; KUNREUTHER; LYSTER, 2016, p. 34).

9 Ambas as abordagens dependem da percepção de que as desvantagens resultantes de restrições anticoncorrenciais podem ser compensadas por vantagens em termos de objetivos econômicos e de bem-estar social. "Quando as medidas estatais impuserem ou favorecerem regras que limitam a concorrência, a Comissão e outros Estados-Membros podem iniciar processos por infracção ao abrigo dos artigos 226. e 227. do Tratado CE. Além disso, as pessoas afetadas negativamente pelas medidas estatais podem propor uma ação de indemnização contra o Estado-Membro por violação do direito comunitário. No passado, o Tribunal de justiça europeu considerou consistentemente que os artigos $3 .{ }^{\circ}, \mathrm{n} .{ }^{\circ} 1$, alínea g), $10, \mathrm{n} .{ }^{\circ} 2$, e $81 .{ }^{\circ}$, n. ${ }^{\circ} 1$, do Tratado CE são violados quando um Estado-Membro exige ou favorece a adoção de acordos, decisões ou práticas que violam as disposições em matéria de concorrência do Tratado, ou reforçam os seus efeitos, ou quando aliena as suas próprias regras de carácter legislativo, delegando aos operadores económicos privados a responsabilidade de tomar decisões que afetem a esfera econômica. Desta forma, o direito da concorrência é capaz de prevenir práticas anticoncorrenciais prejudiciais, mesmo nos casos em que estes tenham sido aprovados ou facilitados pela lei do Estado. A proibição do cartel não os acordos que "tornam a conclusão dos contratos sujeita à aceitação pelas partes de obrigações suplementares que, por sua natureza ou de acordo com o uso comercial, não têm relação com o assunto desses contratos. A vinculação também pode ser proibida como abuso se a empresa que impõe contratos vinculados goza de uma posição dominante. $\mathrm{O}$ artigo 82, alínea d), do Tratado CE contém uma lista de exemplos de abusos de posição dominante e de fóruns fora da lei, utilizando a mesma redação que o artigo 81., n.o 1, alínea e), do Tratado CE”. (VAN DEN BERGH; FAURE, 2006, p. 39-41).

10 Conforme mencionado anteriormente, a imunidade processual é típica dos EUA.

11 "Relativa à indenização das vítimas de desastres naturais". (FRANCE, 1982).

12 "Os grandes números do setor não param por aí. O ressegurador IRB Brasil RE, líder no mercado nacional, registrou lucro líquido recorde de 849,9 milhões de reais em 2016, o que representa um crescimento de $11 \%$ em relação ao mesmo período do ano anterior. Segundo dados da Rating 
de Seguros Consultoria, nos últimos anos, ao se considerar a somatória dos resultados das resseguradoras locais, as margens de rentabilidade têm se situado entre 5\% e 15\% ao ano. Porém, sem a inclusão dos resultados do IRB na conta, o ganho das resseguradoras restantes cai para uma média de $-5 \%$ a $5 \%$ ao ano. O sucesso do IRB pode ser explicado por fatores ligados a melhores resultados na sua carteira de resseguros. Para conseguir esse feito, o IRB renovou importantes contratos nos mercados local e internacional. Essa e outros razões garantiram ao ressegurador uma ampliação em 5 pontos percentuais em sua participação no mercado total brasileiro, passando de 34\%, em 2015, para 39\%, de acordo com dados apurados até setembro de 2016. Entre os principais destaques financeiros de 2016 para a empresa está a receita com prêmios. O volume total avançou 13,6\% em relação a 2015, totalizando 4,9 bilhões de reais. Desse montante, 3,7 bilhões de reais são de prêmios emitidos no Brasil e 1,2 bilhão de reais, no exterior. "A tendência é que o mercado de resseguros cresça ainda mais nos próximos anos, com o surgimento de novos produtos e com a retomada de crescimento da economia brasileira". (O QUE... 2017).

13 Descrição em: Global Facility for Disaster Reduction and Recovery (2017).

14 "O pool de risco é uma das formas de gerenciamento de risco praticadas em seguros. Os acordos de pooling não alteram a perda esperada, mas reduzem a incerteza (desvio padrão) dessa perda. Os acordos de pooling de riscos tornam a perda de cada participante mais previsível". (VALVERDE; TALLA, 2013. p. 248-256).

15 Financiado por contribuições financeiras do Canadá, União Europeia, Reino Unido, França, Irlanda, Bermudas, Japão, Banco Mundial e Banco de Desenvolvimento do Caribe. Os dezesseis países segurados pagam prêmios que variam de acordo com os custos de reconstrução. Depois de desencadeado o gatilho estabelecido para o evento, medido com base em um tremor de terra ou velocidade do vento, os fundos são rapidamente providos por resseguro e mercados de capitais para apresentar resposta imediata após o desastre.

16 Programa de empréstimo de juros baixos, financiado pelo Estado de Connecticut, que fornece financiamento para proprietários de imóveis em municípios costeiros localizados nas Zonas de Inundação. (STATE OF CONNECTICUT, 2015).

17 The Stationery Office (TSO) (2014. cap. 21, part 4: flood insurance).

\section{REFERÊNCIAS}


AFRICAN RISK CAPACITY (ARC). Extreme climate facility (XCF). [S.I.], 31 out. 2016. Disponível em: <http://www.africanriskcapacity.org/2016/10/31/extreme-climate-facility-xcf/>. Acesso em: 10 jul. 2017.

ALLEN, Simon K. et al. Summary for policymakers. In: FIELD, C. B. V. et al. (Ed.). IPCC 2012. Managing the risks of extreme events and disasters to advance climate change adaptation: a special report of the intergovernmental panel on climate change. Cambridge: Cambridge University Press, 2012. p. 3-21.

BEN-SHAHAR, Omri; LOGUE, Kyle D. Outsourcing regulation: how insurance reduces moral hazard. University of Chicago Law School, [S.I.], p. 197-248, 2012.

BERGHMAN, Thomas. A market under (writing) the weather: a recommendation to increase insurer capacity. Law Review., [S.I.], p. 221-229, 2013.

BLAZEY, Patricia; GOVIND, Paul. Financial adaptation challenges for the insurance industry due to climate change. Macquarie Journal Busines Law, [S.I.], v. 4, 2007.

BOTZEN, W. J. Wouter; VAN DEN BERGH, Jeroen C. J. M. Bounded rationality, climate risks, and insurance: is there a market for natural disasters? Land Economics, [S.I.], v. 85, n. 2, p. 265-278, May 2009.

BOTZEN, W. J. Wouter; VAN DEN BERGH, Jeroen C. J. M. Insurance against climate change and flooding in the Netherlands: present, future, and comparison with other countries. Risk Analysis, [S.I.], v. 28, n. 2, p. 413-426, 2008.

BRASIL. Lei no 12.608 de 10 de abril de 2012. Institui a Política Nacional de Proteção e Defesa Civil PNPDEC; dispõe sobre o Sistema Nacional de Proteção e Defesa Civil - SINPDEC e o Conselho Nacional de Proteção e Defesa Civil - CONPDEC; autoriza a criação de sistema de informações e monitoramento de desastres; altera as Leis nos 12.340, de 1 o de dezembro de 2010, 10.257, de 10 de julho de 2001, 6.766, de 19 de dezembro de 1979, 8.239, de 4 de outubro de 1991, e 9.394, de 20 de dezembro de 1996; e dá outras providências. Disponível em:

<http://www.planalto.gov.br/ccivil_03/_ato2011-2014/2012/lei/l12608.htm>. Acesse em: 12 mar. 2018.

BROWN, Craig; SECK, Sara. Insurance law principles in an international context: compensating losses caused by climate change. Alerta Law Reiew, [S.I.], v. 50, p. 541-576, 2012.

BRUGGEMAN, V. Compensating catastrophe victims: a comparative law and economics approach. Alphen aan den Rijn, The Netherland: Kluwer Law International; Frederick, MD: Sold and distributed in North, Central, and South America by Aspen Publishers, 2010. 
CANNARSA, Michel et al. France. In: Michael FAURE; HARTLIEF, Ton (Ed.). Financial compensation for victims of catastrophes: a comparative legal approach. Vienna: Springer Wien, 2006.

CARVALHO, Délton Winter de; DAMACENA, Fernanda. O seguro como instrumento de adaptação às mudanças climáticas e redução de riscos de desastres ambientais. Revista de Direito Ambiental, São Paulo, v. 80, nov./dez. 2015.

FAURE, Michael G. Towards effective compensation for victims of natural catastrophes in developing countries. In: FAURE, Michael G. WIBISANA, Andri (Ed.). Regulating disasters, climate change and environmental harm: lessons from the indonesian experience. [S.I.]: Monograph Book, 2013. cap: 9, p. 243-276,

FAURE, Michael G.; BRUGGERMAN, Véronique. Catastrophic risks and first-party insurance. Connecticut Insurance Law Journal, [S.I.], v. 15, n. 1, p. 1-52, 2008, p. 12.

FAURE, Michael G.; HE, Qihao. Private law and climate disasters: insurance law. In: LYSTER, Rosemary; VERCHICK, Robert R.M.; ELGAR, Edward. Research handbook on climate disaster law: barriers and opportunities. Cheltenham: Edward Elgar Publishing, 2017. cap. 19 Disponível em: <https://ssrn.com/abstract=3089496>. Acesso em: 10 jan. 2018.

FAURE, Michael G.; WIBISANA, Andri. Regulating disasters, climate change and environmental harm: lessons from the Indonesian experience. Cheltenham: Edward Elgar, 2013. p. 243-276, FAURE, Michael; HARTLIEF, Ton. Financial compensations for victms of catatrophes. A comparative legal approach. New Yourk: Springer Wien, 2006.

FELDMAN, Eric A.; FISH, Chelsea. Natural disasters, nuclear disasters, and global governance. Penn Law: legal scholarship repository, paper 1552, p. 1-55, 2015. Disponível em:

htp://scholarship.law.upenn.edu/faculty_scholarship/1552. Acesso em: 14 jul. 2017. FRANÇA. Preâmbulo da Constituição de 27 de outubro de 1946. Disponível em: <http://www.conseil-constitutionnel.fr/conseil-constitutionnel/root/bank_mm/ portugais/constitution_portugais.pdf>. Acesso em: 10 jul. 2017.

FRANCE. Loi n 82-600 du 13 juillet 1982. Relative à l'indemnisation des victimes de catastrophes naturelles Version consolidée au 03 juillet 2017. Disponível em:

<https://www.legifrance.gouv.fr/affichTexte.do?cidTexte=JORFTEXT000000691989>. Acesso em: 15 jul. 2017.

FREEMAN, Paul K.; KUNREUTHER, Howard. Environmental risk management for developing countries. Geneva Papers on Risk and Insurance. Issues and Practice, v. 27, n. 2, p. 196-214, Apr. 2002. Special issue on risk management. 
GLOBAL FACILITY FOR DISASTER REDUCTION AND RECOVERY (GFDRR). [S.I.], 2017. Descrição disponível em: http://www.gfdrr.org/sites/gfdrr.org/files/documents/DRFI_CCRIF_Jan11.pdf Acesso em: 10 jul. 2017.

GOLDBERG, Victor P. The Devil made me do it: the corporate purchase of insurance. Review of Law \& Economics, [S.I.], v. 5, n. 1, p. 541-553, 2009.

HECHT, Sean B. Climate change and the transformation of risk: Insurance matters. UCLA Law Review, [S.I.], v. 55, p. 1559, 2007.

HEMBREE, Diana. Are Hurricane Irma victims getting a fair shake from insurers? Forbes, [S.I.], 13 Sept. 2017. Disponível em: <https://www.forbes.com/sites/dianahembree/2017/ 09/13/ fightingfor-a-fair-insurance-claim-payment-after-hurricane-irma/\#32cea48b6318. Acesso em: 9 set. 2017. KAHNEMAN, Daniel. Thinking fast and slow. New York: Farrar, Strous and Giroux, 2013.

KUNREUTHER, Howard C.; MICHEL-KERJAN, Erwann O. Climate change, insurability of large-scale disasters and the emerging liability challenge. University of Pennsy/vania Law Review, [S.I.], v. 155, p. 1795-1842, 2007.

KUNREUTHER, Howard. Reducing losses from catastrophic risks through long-term insurance and mitigation. Social Research, [S.I.], v. 75, n. 3, p. 905-930, Fall 2008.

KUNREUTHER, Howard; LYSTER, Rosemary. The role of public and private insurance in reducing losses from extreme weather events and disasters. Asia Pacific Journal of Environmental Law, [S.I.], v. 19, p. 29-54, 2016.

KUNREUTHER, Howard; MICHEL-KERJAN, Erwann. Managing catastrophic risks through redesigned insurance: challenges and opportunities. In: DIONNE G. (Ed.). Handbook of insurance. New York: Springer, 2013. p. 517-546.

KUNREUTHER, Howard; PAULY, Mark. Rules rather than discretion: lessons from Hurricane Katrina. Journal of Risk and Uncertainty, [S.I.], v. 33, n. 1, p. 101-116, 2006.

KYDLAND, Finn; PRESCOTT, Edward. "Rules rather than discretion: the inconsistency of optimal plans," Journal of Political Economy, [S.I.], n. 85, p. 473-91, 1997.

LINNEROOTH-BAYER, Joanne; MECHLER, Reinhard; HOCHRAINER-STIGLER, Stefan. Insurance against losses from natural disasters in developing countries: evidence, gaps and the way forward. Journal of Integrated Disaster Risk Management, [S.I.], v. 1, n. 1, p. 76-77, 2011.

LYSTER, R. Climate justice and disaster law. Cambridge: Cambridge University Press, 2015. 
MCGEE, JaVale et al. Writing the fine print: developing regional insurance for climate change adaptation in the Pacific. Melbourne Journal of International Law, [S.I.], v. 15, n. 2, p. 154-170, 2014.

MEZZAROBA, Orides; MONTEIRO, Cláudia Servilha. Manual de metodologia da pesquisa no direito. São Paulo: Saraiva, 2009.

MICHEL-KERJAN, Erwann; MARCELLIS-WARIN, Nathalie. Public-private programs for covering extreme events: the impact of information distribution on risk-sharing. Asia-Pacific Journal of Risk and Insurance, [S.I.], v. 1, n. 2, p. 21-49, 2006.

MICHEL-KERJAN, Erwann; KUNREUTHER, Howard. Redesigning flood insurance. Science, v. 333, n. 6041, p. 408-409, 2011.

MILLS, Evan. A global review of insurance industry responses to climate change. The Geneva Papers on Risk and Insurance-Issues and Practice, [S.I.], v. 34, n. 3, p. 323-359, 2009.

MILLS, Evan; LECOMTE, Eugene. From risk to opportunity: how insurers can proactively and profitably manage climate change. [S.I.]: Ceres Report, 2006. Disponível em:

<http://evanmills.lbl.gov/pubs/pdf/kiplinger-march-2007.pdf>. Acesso em: 12 jun. 2017.

O Que é o mercado de resseguros e porque ele está em crescimento. Exame, São Paulo, 03 mar. 2017. Disponível em: https://exame.abril.com.br/negocios/o-que-e-o-mercado-de-resseguros-epor-que-ele-esta-em-crescimento/. Acesso em 06 jun. 2018.

PRIEST, George L. The government, the market, and the problem of catastrophic loss. Journal of risk and Uncertainty, [S.I.], v. 12, n. 2, p. 219-237, 1996.

RASCHKY, Paul A.; WECK-HANNEMANN, Hannelore. Charity hazard - a real hazard to natural disaster insurance? Environmental Hazards, [S.I.], v. 7, n. 4, p. 321-329, 2007.

ROCHA, Leonel Severo. Introdução à teoria do sistema autopoiético do direito. Porto Alegre: Livraria do Advogado, 2018.

ROTH, Richard J.; KUNREUTHER, Howard (Ed.). Paying the price: the status and role of insurance against natural disasters in the United States. Washington, DC: Joseph Henry Press, 1998.

SÃO BERNARDO DO CAMPO. Defesa Civil. Enchente, inundação, alagamento ou enxurrada? São Bernardo do Campo 19 jun. 2011. Disponível em: <http://dcsbcsp.

blogspot.com.br/2011/06/enchente-inundacao-ou-alagamento.html>. Acesso em: 9 mar. 2018. SCHOEMAKER, Paul J. H; KUNREUTHER, Howard C. An experimental study of insurance decisions. Journal of Risk \& Insurance, [S.I.], n. 46, v.4, 603-618, 1979. 
STATE OF CONNECTICUT. Department of Emergency Services and Public Protection. Division of Emergency Management and Homeland Security. Draft final: flood management general certification for certain program activities under the FEMA hazard mitigation assistance grant programs. Connecticut, July.2015. Disponível em:

<http://www.ct.gov/demhs/lib/demhs/hmgp/2015/floodcert.pdf>. Acesso em: 10 jul. 2017. SURMINSKI, Swenja; ORAMAS-DORTA, Delioma. Flood insurance schemes and climate adaptation in developing countries. International Journal of Disaster Risk Reduction, [S.I.], v. 7, p. 154-164, 2014.

SWISS RE. Managing climate and natural disaster risk. Zurich, 2016. Disponível em: <http://reports.swissre.com/corporate-responsibility-report/2016/cr-report/risk-landscape/ourtop-topics/managing-climate-and-natural-disaster-risk.html>. Acesso em: 10 jun. 2017.

SWISS RE. Sigma 1/2018: Natural catastrophes and man-made disasters in 2017: a year of recordbreaking losses. Zurich, Apr. 2018.Disponível em: <http://www.swissre.com/ library/publicationsigma/sigma_1_2018_en.html. Acesso em: 19 maio 2018.

THE STATIONERY OFFICE (TSO). Water Act 2014. In: THE STATIONERY OFFICE (TSO). The flood reinsurance scheme. Norwich, 2014. cap. 21, part 4: flood insurance. Disponível em: <http://www.legislation.gov.uk/ukpga/2014/21/pdfs/ukpga_20140021_en.pdf>. Acesso em: 10 jul. 2017.

VALVERDE, Raul; TALLA, Malleswara. Risk reduction of the supply chain through pooling losses in case of bankruptcy of suppliers using the black-scholes-merton pricing model. In: CHAUBEY, Yogendra P. (Ed.). Some recent advances in mathematics and statistics. [S.I.], World Scientific, 2013. p. 248-256. Disponível em:

https://spectrum.library.concordia.ca/979165/1/Valverde_Edited_YC.pdf. Acesso em abr. De 2018. VAN DEN BERGH, Roger; FAURE, Michael. Compulsory insurance of loss to property caused by natural disasters: competition or solidarity. World Competition, [S.I.], v. 29, n. 1, p. 25-54, 2006. MEZZAROBA, Orides; MONTEIRO, Cláudia Servilha. Manual de metodologia da pesquisa no direito. São Paulo: Saraiva, 2009.

Trabalho enviado em 16 de julho de 2018 Aceito em 11 de janeiro de 2019 